\title{
Comparison of recruitment yield in prevention and therapy trials
}

\author{
Cindy Cooper*, Adjoa Asante, Danny Hind, Stephen Walyers \\ From 2nd Clinical Trials Methodology Conference: Methodology Matters \\ Edinburgh, UK. 18-19 November 2013
}

\section{Introduction}

The literature demonstrates that only $31 \%$ of trials are successful in recruiting $100 \%$ of their original target and $45 \%$ recruit fewer than $80 \%$ (McDonald, 2006). It has been proposed that in prevention trials only one in twenty of patients screened are enrolled into trials and for medical care therapy trials the figure is nearer 1 in 5 (Spilker and Cramer, 1992).

\section{Aims}

To compare recruitment in therapeutic trials with that in prevention trials to test Spilker and Cramer's hypothesis that there is a large difference between the two types of studies.

\section{Methods}

Data from all stages of the recruitment process were extracted from existing systematic reviews of prevention and therapy RCTs focussing on the use of metformin monotherapy in diabetes as a case study.

\section{Results}

Twenty six diabetes prevention and twenty- seven diabetes therapy papers were reviewed. The recruitment yield, defined as the percentage of people recruited to people screened, in the diabetes prevention studies was $11 \%$. The recruitment yield of the diabetes therapy studies was almost five times higher at $53 \%$.

\section{Conclusions}

Recruitment yields in prevention and therapy trials, were higher than Spilker and Cramer's predictions of $5 \%$ and $20 \%$ respectively. However, there is a large difference between recruitment yields to the two types of studies and this should be taken into consideration when estimating

University of Sheffield, Sheffield, UK

(C) 2013 Cooper et al; licensee BioMed Central Ltd. This is an Open Access article distributed under the terms of the Creative Commons Attribution License (http://creativecommons.org/licenses/by/2.0), which permits unrestricted use, distribution, and reproduction in any medium, provided the original work is properly cited. recruitment rates for future trials. Reporting of data at all stages in the recruitment process needs to be improved to facilitate better estimation of recruitment yields.

Published: 29 November 2013

doi:10.1186/1745-6215-14-S1-0112

Cite this article as: Cooper et al:. Comparison of recruitment yield in prevention and therapy trials. Trials 2013 14(Suppl 1):0112.

Submit your next manuscript to BioMed Central and take full advantage of:

- Convenient online submission

- No space constraints or color figure charges

- Inclusion in PubMed, CAS, Scopus and Google Scholar

- Research which is freely available for redistribution
- Thorough peer review

- Immediate publication on acceptance 